\title{
Controlling the Fourth Industrial Revolution: Education and Technology Fusing Tendency Research
}

\author{
Yizhen Liu* \\ Engineering Practice Center \\ Liaoning Institute of Science and Technology \\ Benxi, China \\ lnbxlyz@126.com \\ Yanming Wang \\ Engineering Practice Center \\ Liaoning Institute of Science and Technology \\ Benxi, China \\ 17936988@qq.com
}

\author{
Bo Gao \\ Engineering Practice Center \\ Liaoning Institute of Science and Technology \\ Benxi, China \\ 1678995487@qq.com \\ Li Liu \\ Engineering Practice Center \\ Liaoning Institute of Science and Technology \\ Benxi, China \\ 57684940@qq.com
}

\begin{abstract}
After the fourth Industrial Revolution comes, the whole world facing digitized era, it is imperative to the revolution of fusing education and technology in China. This article deals with virtual reality plus teaching; virtual/cloudy computing plus teaching; big data plus teaching; artificial intelligence plus teaching, the goal is to join these three aspects together and to provide education and technology issue, to comb out different data and methods of research.
\end{abstract}

Keywords-The fourth Industrial Revolution; education and technology; fusing; development tendency

\section{THE IMPACT OF THE FOURTH INDUSTRIAL REVOLUTION ON GLOBAL EDUCATION}

In January 2016, the world economic BBS annual meeting was held in Davos of Switzerland, the topic of which was about the fourth industrial revolution. The fourth industrial revolution is defined as: collection Internet of things, 3d printing, robots, artificial intelligence and big data fusion technology in the development of intelligent information social structural physical system dominated by production revolution. The fourth industrial revolution is using digital power to revolutionize industries, and its arrival will have a profound impact on the economy, education, society and human behavior Under the trend of the fourth industrial revolution, the social structure will change and be bound to affect the change of global education development direction. In view of the trend of world economic development, China's education reform is imperative.

\section{RESEARCH ON CHINA'S DEVELOPMENT TREND OF EDUCATION AND TECHNOLOGY FUSION IN THE FOURTH INDUSTRIAL REVOLUTION}

Under the lead of the fourth wave of industrial revolution, education technology and the change of learning fusion is imminent. Using smart media, Internet of things, and artificial intelligence and other advanced IT technology can change the way of education and improve the efficiency of education teaching effectively has been the main direction of education and technology fusion development.

\section{A. Virtual reality technology}

Virtual Reality (VR) was proposed by Jaron Lanier, founder of VPL Research in America in 1989 [1]. In a broad sense, virtual reality technology is the simulation of virtual phenomenon (3d visualization) or real, multi-sensory 3d world [2]. Virtual reality technology, which uses computer technology as the core, is combined with digital image processing, computer graphics, computer simulation technology, man-machine interface technology, multimedia technology, sensor technology, and other information technology and other modern high-tech, means to generate a virtual environment (simulation in the real world environment, the human subjective environment and invisible for human beings in the real world environment, etc.). Users interact naturally with objects in the virtual world (such as voice, hand movements, the rotation of the head, feet walk, etc.) through special input devices: the game handle/rocker, the $3 \mathrm{~d}$ data gloves, position tracking, eye movement, motion capture device garment (data) and output devices: wearing a display, 3d display, 3d glasses, cavernous stereo display, etc.. Using the natural way to operate the virtual object and get the real-time stereo feedback, so as to achieve the same feelings as the real world through vision, hearing and touch.

\section{B. Virtual reality technology plus education}

1) To construct campus information management/teaching service platform

In the construction of campus informatization, VR technology can be used to establish the campus/teaching 
information management system and its own service platform. With the help of virtual realistic teaching, students would make traditional study into overturning experience, which makes it possible for immersion learning. Also the construction, as a revolutionary teaching mode, will be the leading position so as to effective teaching level, and increase the teaching to be reliable, controllable and visual in classroom, boosting the class interactive activities diversely and efficiently. VR campus network management/service platform is not only a VR teaching, but also a uniting of the whole college, VR recording, VR live anywhere MOOC SPOC etc. It supports the following teaching functions such as voice check attendance and mobile teaching, WeChat App teaching etc. It also accumulates the teaching data and content, including the accumulation of vast amounts of knowledge base, database, meanwhile enhances the teaching effect, evaluates teaching process, analyzes teaching data and makes decision on relevant teaching and teaching reform. Advanced campus information network management/teaching service platform can make the teaching process visualization, the teaching effect digital plasticity, teaching evaluation, teaching data automation, and the teaching management process simple and efficient, the teaching process easily, and students' learning effect ratio increases.

\section{2) $V R / A R$ (virtual reality) classroom}

Based on the 3I feature of virtual reality, namely Interaction, Immersion and Imagination, virtual classes can be constructed to make students have a strong sense of participation, Immersion and interconnection. According to the professional quality and combining the course characteristics, if be used appropriately and reasonably, immersion teaching experience can pull any scene into the classroom, whether in assembly and maintenance of computer hardware, mechanical equipment and car cognitive, medical anatomy and aircraft simulation driving and so on a number of professional, let the students entered the classroom at any time. It has replaced the conventional means of traditional education, and can maximize stimulate students' interest in learning, improve the students' imagination, and further promote and guide the cultivation of students' innovative thinking. The students can interact directly with all sorts of objects in a virtual environment, and participate in the learning process through a variety of forms, so as to gain the biggest realistic learning experience. The students can be effectively turned from passive learning state naturally to a state of active learning and truly achieve the result of half the effort. In addition, virtual classroom can reduce education cost, improve security, and teach students in accordance with their own needs. Students can control the progress and fully reflect the sharing and fairness of education resources.

3) Build VR/AR remote education and experimental training center

Personal connection is three-dimensional in virtual reality. People, who are from the original space, break the limitation of time and space; can make full use of the remote education teaching. Students who break the remote teaching space, time limit, attend the study through virtual reality system, choose their own learning place and time, create humanized, personalized learning model, and learn a variety of courses. In virtual course, teachers and students study and discuss together, collaborative interaction study, improve the effect of learning efficiently. In practice and experiment course, students can directly involve in various experiments such as skills training at home, and the school which needn't be obsessed with the school funding problems such as classroom, laboratory equipment, can make use of virtual reality technology to establish the social training institutions, which is suitable for students and on-the -job staff who want to learn and be interested in skills training, etc.

\section{Cloud computing plus education}

Cloud Computing is the product of integration of traditional computer technology and Network technology, such as Grid Computing, Distributed Computing, Parallel Computing, Utility Computing, Network Storage Technologies, Virtualization, Load Balance [3]. At present, there are three kinds of commonly used formats, cloud computing, infrastructure as a service (IaaS, providing on-demand using virtual servers, such as Amazon EC2), Web service or "platform as a service" (PaaS), provide the API or development platform for customers to create their own applications in the cloud, software as a service (SaaS), such as Salesforce.com's CRM software [4].

Cloud computing is a network application mode provided by Google, and the long-distance data center is made up of millions of computers and servers connected together, which constitute a computer cloud, to store huge data information and application services. It greatly simplifies the user terminal equipment; the complex work is moved to the cloud computing service terminal. The most common use in teaching is network storage technology, which can create cloud library, cloud technology learning lab and cloud service campus education teaching platform, completely solves the problem that the original resource is scattered and data is difficult to synchronize. It not only simplifies the complexity of the growing architecture, but also reduces the cost of teaching application software services (educational administration management software, student management software, financial management software, etc.), teaching equipment and high maintenance. The structure of education teaching service cloud platform is shown in Fig .1 below.

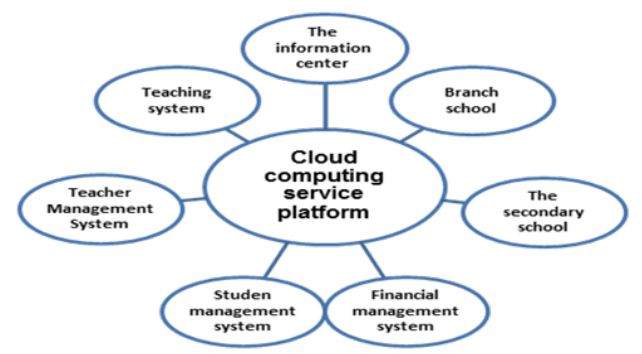

Fig. 1. Campus education teaching service cloud platform

1) Individualized management and personalized learning methods

In the teaching system, teachers use cloud computing to support teaching and upload a lot of resources to service teaching, and to establish class management in a professional manner. Teachers can also establish management mechanism for different learning situations of students, and realize 
informatization, individual management and teaching. Teachers and students can study and communicate online, and further improve their teaching in spare time. Students learn relevant content according to their different learning ability, and individualize their learning methods according to their own actual situation. In the learning process, it is convenient and convenient to access the relevant learning materials at any time. Teachers can adjust the teaching content, schedule and methods according to students' learning and mastery and make different personalized learning plan according to students' different learning ability, and distribute various teaching materials etc. All these methods not only improve the teaching quality, but also fully mobilize the students' learning interest and initiative, greatly improve the effectiveness of learning, and complete the teaching goal, and make the teaching process more rational, humanized and scientific.

\section{2) Share resources, work together, build smart campus}

Cloud platform can optimize teaching management, and be coordinated between each campus, branch office, teaching development, scientific assessment. It can also help the interaction among students from different departments, interdisciplinary study, and shared network resources and so on. Cloud platform has created a high digital, high interactivity, high intelligence, high efficiency of the new education teaching mode. Cloud computing network can make full use of education resources, also create regional education teaching training system, and reduce the imbalance of education resources between urban and rural areas, different regions and schools. All students can share the network resources, and will have the right to fair education.

\section{Big data plus education}

\section{1) The development of big data}

Actually, as early as 1980, the world famous futurologist Alvin Ttoffler referred to Big Data (Big Data) as 'the third wave of reality" [5] in his book "Third Wave". McKinsey defines big data as data sets that exceed the ability of typical database software to collect, store, manage and analyze [6]. Big data technology is not a description of big data, but the ability to quickly acquire valuable information in large, diverse data, effective analysis and processing of massive data in real-time. The $4 \mathrm{~V}$ features of big data are generally recognized in the industry, namely, Volume (large scale), Variety, Velocity(fast), Value(sparse Value).Big data sources are complex and extensive, its types are complex and difficult to deal with, but the process is consistent, data acquisition, data integration and processing, data analysis and mining, the data show, altogether four steps [7]. The process and key techniques are shown in Fig. 2 below.

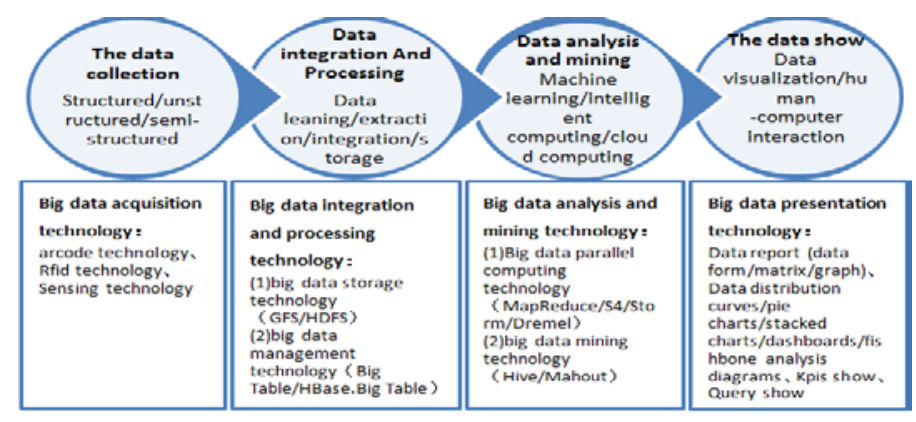

Fig. 2. Data processing flow and key technologies of big data

\section{2) Education big data}

Education big data is defined as the broad and narrow sense, and the generalized education big data refers to all data comes from everyday education activities and human behavior, narrow education big data refers to the learner behavior data [7]. Education big data promotes the campus to digital, networked, intelligent comprehensive development. It can promote the scientific management of education, more comprehensive education evaluation and scientific research indepth, intelligent, personalized learning education mode and so on.

a) To develop personalized guidance scheme for learners

Personalized learning is a new type of teaching mode, which emphasizes learners as the center, and the individual learners' studying characteristics are different and they take targeted, targeted intervention to study and put forward the guidelines, so that learners improve learning state and achieve the optimal effect. To establish a learning database for different students, and the data source collection comes from learning behavior, learning resources and basic information of the learner's learning process, such as courses, learning time, online reading, test scores, assignments, interaction, network classroom, learning interest and hobbies, resource collection and access downloads, school participation at all levels and so on. These data are collated and analyzed, and the learning trajectory analysis report is completed by using big data correlation technology. Through data mining and other tools to evaluate the learners' problems and intelligent artificial learning intervention, to predict learners' future learning, and improve learning system, correcting, and adjust the teaching methods and contents, and guide and customize the learner's learning solutions. The traditional teaching mode is transformed into personalized learning model based on learners.

b) The new model of precise teaching is created to optimize the teaching quality of educators

Kenneth. Cook and Schon Berg in their co-authored book (Learning with Big Data: The Future of Education), they argue that the most important part of big data is not the technology or algorithms, but data itself, who has access to data or who has Data, who has power [8]. In the past, teachers used their teaching experience to make teaching plan and content adjustment. Now, the collected data can be used to calculate and analyze and carry out targeted teaching. If schools have no data ecosystem, some free online software can be used to 
support data analysis and diagnosis teaching. To adjust teaching methods and content accurately, through different channels, we can use data from different sources, to achieve personalized teaching and precise teaching.

c) The teaching management of education, which is refined and intelligent, provides scientific decision-making

In school teaching management, it used to be a rough and intuitive management mode. One of the reasons for this is that it is impossible to master the teaching management data in real time, and the data is important support and adjustment for administrators.Through the integration and analysis of student information, teacher information and education teaching management data, the school can help education administrators to monitor the management status of schools and institutions dynamically, timely discover the problems in management and teaching, conduct education teaching intervention and evaluate the results of intervention, to provide scientific decision to optimize the education teaching management, and make the education teaching management rationalization, humanity and science, to change the education teaching management mechanism.

\section{E. Artificial intelligence plus education}

1) Artificial intelligence (AI)

Artificial intelligence was first proposed at Dartmouth in 1956, which is a multidisciplinary technology that integrates psychological cognition, machine learning, emotion recognition, human-computer interaction and data save, decision making. It is a new technology and science in the research and development of the intelligent theory, method, technology and application system for simulating, extending and expanding human beings. The main content of the artificial intelligence science research: knowledge representation (including planning and decision making), automatic reasoning and search methods, machine learning and knowledge acquisition, knowledge processing, natural language understanding (including speech, and semantic recognition, automatic translation), computer vision, image recognition, intelligent robot, automatic programming, etc. At present, it has been applied in robot, economic and political decision-making, control system and simulation system. The main core technologies of artificial intelligence are expert system, machine learning and deep learning, machine learning and pattern recognition.

\section{2) Artificial intelligence plus education}

a) Intelligent Tutoring System

Intelligent teaching system (ITS) is a complex software system composed of expert module (knowledge base), student module, teaching module and intelligent interface [9]. Intelligent teaching system is the main representation of artificial intelligence on education, which is the inevitable trend of artificial intelligence developing on education. The intelligent teaching system is an open human-computer interaction system based on the students as the center and the computer as the medium, using the computer simulation teaching expert's thinking process [10]. It combines the activities of knowledge experts, teachers and students, analyzes and understands the students' ability (ability to learn, grade level, mental status), such as automatic diagnosis of students' learning level and existing problems. Through the students' dynamic behavior to make scientific and correct guidance, correct the learning methods, intelligently play the guidance and reminder function, and provide targeted solutions and suggestions, develop learning programs and learning plans to develop students' ability.

\section{b) Digital classroom development}

Digital classroom is composed of three parts : network platform, massive resources and high-tech equipment, which can be understood as using text, voice, image and animation and other multimedia teaching interaction to make the teaching content of the vitality, interest and experience, so as to mobilize enthusiasm and subjective initiative of students. Through an extension of the classroom network, let the students learning approach with real-time convenience and continuity, fully develop the students' innovation consciousness and innovation ability, and improve the teaching efficiency of a new type of teaching mode, is the use of high-tech means of information technology, realize the traditional unidirectional to bidirectional interactive classroom teaching type of new teaching idea. If the main method of classroom teaching today is "from principle to application", the teaching method of robot is "from case to principle". In 2014, EBook Library McGrawHill online Library released its latest digital platform, which offers more than 2000 kinds of searchable digital books, collects information from 2,000,000 students and create the adaptive learning experience by artificial intelligence for each student. The study of digital classroom will be one of the teaching modes in the future.

\section{c) Reshape online education}

Primary and secondary schools, vocational education, higher education, online education has become the main force of the online education in our country. According to research, China's online education market is 83.97 billion yuan in 2013 . Traditional online education mode, in which teachers and students is a one-to-many relationship, lacks of pertinence for different students' learning ability. Personalized online education will become one of the trends of future education wisdom. The market size of education online will grow even faster, if the artificial intelligence technology can be used for online education in improving teaching interactive experience and delivering personalized teaching contents and methods into online education in classroom.

\section{CONCLUSION}

The advent of the fourth wave of industrial revolution will not only lead to social change, also be bound to the revolution of education. Every new technological revolution is pushing education. Change of virtual reality technology, cloud computing, artificial intelligence and other new technology and the advent of the era of big data will cause learning education and social education of revolutionary change, essentially affects People's Daily lives, learning style and cognitive thinking principle of the world. Education reform is to achieve efficient teaching to promote effective learning as the ultimate goal. In order to further realize the internationalization and diversification of education accelerate the benign and high- 
speed development of education in China, the integration of education and new technology needs further research and practice.

\section{REFERENCES}

[1] Li Xinhui, Chen Meilan. Virtual reality technology and application [M].Beijing: Tsinghua University press, 2016.8.

[2] An Weihua. Virtual reality technology and its application [M]. Beijing: Tsinghua university press, 2014.4, page 7.

[3] Wang Peng. Approaching cloud computing [M]. Beijing: people's post and telecommunications press, 2009.

[4] Zhang Weimin. Cloud computing: profoundly changing the future [M]. Beijing: science press, 2009.

[5] Alvintolev, Huang Mingjian. The third wave [M]. Beijing: critic press, 2006:19-25.
[6] McKinsey. Big data: the next frontier of innovation, competition and productivity [R/OL] [2011]http://wenku.baidu.com/link? URL=HyLEGta-8aZ w-8d8kNcOOKQqjzkyz2z7W Gvc9fA_vcu288Aj74QMGyPDRQTr7zC3z_JR3Y1di SMCyHAmg9Mv YseqhbXrP4IB39XaJbUCFC.

[7] Xu Peng Wang Yining, Liu Yanhua etc. Large data perspective study change - the United States through education and learning data mining analysis to promote the teaching and learning, "the report read and enlightenment [J]. Journal of distance education, 2013 (6): 11-17.

[8] Zhao Zhongjian, Zhang Yannan. The study with the big data colleagues and education - the author of the big data era, professor schenberger and Mr.Kuker [J]. Global education outlook, 2014, (12): 3-9.

[9] Wu Jingjing. Several questions about the application of artificial intelligence education [J]. Exploration and practice, 2012.

[10] Jiao Jialin, Xu Liang xian, Dai Kechang. Application of artificial intelligence in intelligent teaching system [J]. Computer simulation, 2003.20(8).49-52. 